\title{
Knowledge, Attitudes and Practices of Pregnant Women in relation to their Diet at the Reference Health Centre of Commune VI (Bamako, Mali)
}

\author{
Berthe $\mathrm{M}^{1.2^{*}}$, Khadijitou $\mathrm{W} \mathrm{A}^{2}$, Diawara $\mathrm{F}^{1}$, Kone $\mathrm{O} \mathrm{M}^{1}$, Diallo $\mathrm{H}^{2}$, Konake $\mathrm{M}^{3}$, Konate $\mathrm{F} \mathbf{B}^{1}$, Leila $\mathrm{A}^{1}$, Telly $\mathrm{N}^{4}$, \\ Sidibe $\mathrm{F}^{1}$ and Akory $\mathrm{AA}^{1}$
}

${ }^{1}$ National Institute of Public Health - Bamako-Quarter of the

Hyppodrome

${ }^{2}$ National Institute of Training in Health Sciences; Common $V$ Reference Health Centre

"Corresponding author

MAMADOU BERTHE, National Institute of Public Health - Bamako-Quarter of the Hyppodrome, National Institute of Training in Health Sciences; Common V Reference Health Centre, Mali

${ }^{3} \mathrm{C}$ between Common Vi Reference Health (CSRéf CVI)

Submitted: 10 Oct 2020; Accepted: 17 Oct 2020; Published: 03 Nov 2020

${ }^{4}$ Department of Teaching and Research in Public Health/Faculty

of Medicine and Odontostomatology (DERSP/FMOS)

\begin{abstract}
Introduction: Worldwide, nearly half of all pregnant women suffer from anaemia; 9.8 million of them suffer from night blindness. In the csréf de la commune VI during 2018,36\% of pregnant women were screened for malnourished and out of 10624 live births 660 children had a low birth weight. That's why we conducted this study to assess the level of knowledge, attitudes and dietary practices of pregnant women at the Commune VI Reference Health Centre.
\end{abstract}

Materials and methods: This study, which took place at the csréf de la commune VI from 10 December to 09 January 2019, was mixed (qualitative and quantitative). The objective was to assess the level of knowledge, attitudes and practices of pregnant women in relation to their diet. We used reasoned non-probabilistic sampling. The analyse was made on Epi info, the graphics generated by Excel and the writing made on the Word.

Results: The results confirmed that 38\% of pregnant women do not know what is recommended as food during pregnancy. They did not know in 54\% of cases that the ideal weight gain during pregnancy has real impacts on their health and that of their child. A small proportion of women (10\%) know that folate is beneficial in early pregnancy. (With regard to physical activity only 4\% continued physical exercise during pregnancy. The majority do not seem to know the risks of toxoplasmosis and listeriosis (12 and 4\%) respectively. Four out of nine food groups are usually consumed by pregnant women - cereals 94\% of the time. Thirty-six percent of women have a low food diversity score.

Conclusion: At the end of our study, major efforts must be made in raising awareness to improve the level of knowledge of pregnant women at the csréf de la commune VI.

Keywords: : Pregnancy, Vitamins, Nutrients, Diet, Weight gain, Complications

\section{Introduction}

A good adequacy of dietary intakes is a determining factor in the harmonious course of pregnancy and aching [1]. During this very special period, the pregnant woman must cover the increased nutritional needs of her body as well as those of the unborn child. Malnutrition from the second trimester of pregnancy can lead to intrauterine growth retardation (ICU) and fetal hypotrophy. It can lead to the birth of low birth weight (NPP), to the risk of pathologies in adulthood, such as type 2 diabetes and diseases because diovascular [1] .
The risk of pregnancy complications such as birth defects or preeclampsia is higher in obese women. They have higher plasma blood glucose levels than women with a normal body mass index (BMI), and the fetal insulin level is also higher [2].

The consequences of deficiencies are manifold for women of childbearingage, during pregnancy and breastfeeding, for infants and children. They negatively influence the development, especially cognitive, of the child, cause loss of productivity and education, increase morbidity and maternal mortality. Deficiencies in early 
childhood have implications for adulthood and are a risk factor for future generations with significant economic repercussions [3]. Maternal micronutrient deficiencies can reduce birth weight and compromise child development and survival; maternal iodine deficiency is associated with birth defects and mental retardation in children. In India, vitamin B12 deficiency has been linked to increased risk of diabetes.

Worldwide, it is estimated that nearly half of all pregnant women suffer from anaemia; 9.8 million of these women suffer from night blindness. UNICEF is estimated to have 19.1 million pregnant women in 2016, a significant proportion of whom in Africa and Southeast Asia have low rates of serum retinol [2].

Every year, some 30 million children are born in developing countries with growth disorders due to nutritional deficiencies during pregnancy [4].

The highest burden of vitamin A and anaemia is found in the African Region and Southeast Asia of the World Health Organization (WHO) [3-4].

In Mali in 2013, according to the Demographic and Health Survey (EDSM V), one in two women was anemic (51\%) [5-6]. There are variations depending on certain socio-demographic and economic characteristics. Pregnancy influences the prevalence of anaemia, in fact, $60 \%$ of pregnant women are anemic. The proportion of anaemic women increases overall with parity, ranging from $48 \%$ among mothers with a child (primipare) to $56 \%$ among mothers of 4-5 children (multipare) [6].

The same survey (EDSM V) observes, levels of consumption of foods rich in vitamin A and iron in women aged 19 to 49, respectively, are $53 \%$ and $47 \%$ respectively in the country as a whole [6].

The government of Mali has adopted a National Nutrition Policy (2012-2021), which aims to help ensure that every Malian has a nutritional status that is satisfactory for their well-being and for national development. The fight against micronutrient deficiencies is the third of the 14 strategic axes of this policy [7].

In Mali the diet is mainly based on cereals (mil, rice, sorghum, maize). These basic foods are added to dairy products, and to a lesser extent legume, roots and tubers (sweet potatoes, yams, manioc) and fruits and vegetables [8]. In urban areas, patterns of food consumption are changing and rice is prominent. At the level of the csréf de la commune VI during $2018,36 \%$ of pregnant women were screened for malnourished (DHIS2) and out of 10624 live births 660 childrenhad a low birthweight (PPN). Based on this result we conducted amixed study (qualitative and quantitative) to assess the level of knowledge, attitudes and dietary practices of pregnant women at the reference health center of commune VI.

The general objective of this work was to assess the level of knowledge, attitudes and dietary practices of pregnant women in antenatal consultations in the Reference Health Centre of commune VI of Bamako district.

The specific objectives were:

- Describe the level of knowledge, attitudes and practices about feeding pregnant women at the csréf de la commune VI; - Describe the food consumption profile of pregnant women; - Determine the dietary diversity score of pregnant women.

\section{Materials and Methods}

Type of Study: This is a comparative qualitative and quantitative study that took place over a one-month period from December 10 , 2018 to January 9, 2019.

Study Framework: Sogoniko's Maternity Hospital is located in Commune VI of the Disrict of Bamako on the right bank of the Niger River.

The maternity ward consists of two blocks: A block: A delivery room consisting of six boxes, an observation room, a room for a row of diapers, a screening room for cervical cancer, a room for interns and a room for the guard team.

Three rooms for antenatal consultation, a gynecological consultation room, a PMTCT unit, a PF unit and a large waiting room. The other block consists of one room for $\mathrm{u}$ post-um consultations and another for the registration of birth certificates.

\section{Study population: \\ Target population}

All pregnant women in the commune VI.

\section{Population source}

All the women seen in antenatal consultation at the csréf de la commune VI during the period.

\section{Inclusion criteria}

Any pregnant woman seen in antenatal care during the period agreeing to be interviewed.

\section{Exclusion criteria}

Any pregnant woman seen in antenatal care during the period that does not agree to participate in the study.

\section{Sample size}

A non-probabilistic sample of 50 women, i.e. A reasoned choice, was formed.

\section{Collection technique and tools:}

Data Collection Survey Technique

The survey was based on two (2) complementary methodological approaches:

\section{Qualitative survey:}

Pregnant women seen in antenatal care. An individual interview was addressed to each pregnant woman agreeing to participate in the study.

\section{Quantitative survey:}

The analysis of the specific nutritional needs of the pregnant woman. The woman's score was determined from anthropometric measurements.

Tools: The tools used are the questionnaires, the food composition table, the individual CPN cards, the CPN registry. 
Variables

- The qualitative variables: education level, ethnicity, pregnant woman's personal history, knowledge, attitudes and practices regarding the pregnant woman's diet, food consumption profile and dietary diversity of pregnant women.

- Quantitative variables: age, weight, height, parity and body mass index.

\section{Data processing and analysis}

After counting the records, we corrected the data to ensure their completeness, consistency and consistency. Then the data was analyzed by the software Epi info 7.0, EXCEL and the writing was done by the WORD.

\section{Validity criteria}

Internal validity: The method used has been used toassess the level ofknowledge, attitudes and dietary practices of the pregnant woman seen in antenatal consultation in the Community VI Health Centre.

External validity: The expected results will be generalized on the population to be studied.

\section{Ethical considerations}

After information and obtaining written, informed consent from pregnant women, participation was absolutely voluntary.

\section{Results}

The survey identified 50 pregnant women on their knowledge, attitudes and practices in relation to their mode of feeding at the csréf de la commune VI from 10 December 2018 to 09 January 2019. In this part we will only address the Knowledge and Attitudes part.

Socio-demographic characteristics of pregnant women in the CAP study at the csréf de la commune VI from $\mathbf{1 0}$ December 2018 to 09 January 2019:

The age of the majority of the women in our sample was between 25 and 34 years $(50 \%)$ with an average age of $26.84 \pm 27$. One third of the women in our study have fundamental level (34\% for the second cycle and $6 \%$ for the first cycle). The percentage of spouses inthe higher education level was $36 \%$, while spouses with no education level represented d 'instruction représentaient $28 \% . \%$.

Households were the most frequent (50\%), followed by shopkeepers (24\%), "others" (14\%) and students (12\%).

Pregnancy-related data; four groups were formed:

- Two-thirds of the women surveyed had at least 2 children.

- In the 0-1 child group, 15 were at their first pregnancy.

- In the group of women of 4 children and more one had 10 children; another had 9 children; six had 5 children and seven women had 4 children each.

Knowledge, attitudes and practices regarding pregnant women's diet: - Knowledge of pregnant women's diet:

Tablea I: Recommended and not recommended foods during pregnancy cited by women seen in CPN at the csréf de la commune VI de Bamako from December 2018 to January 9, 2019.

\begin{tabular}{|l|l|l|}
\hline $\begin{array}{l}\text { Recommended and not recom- } \\
\text { mended foods during pregnancy }\end{array}$ & $\begin{array}{l}\text { Number of } \\
\text { staff(No.50) }\end{array}$ & $\%$ \\
\hline Recommended & & \\
\hline Don't know & 19 & 38 \\
\hline Salad, vegetables & 19 & 38 \\
\hline Fish/meat & 9 & 18 \\
\hline Fruits & 13 & 26 \\
\hline Liver & 5 & 10 \\
\hline Not recommended & & \\
\hline Don't know & 25 & 50 \\
\hline Manioc & 6 & 12 \\
\hline Meal of the day before & 6 & 12 \\
\hline Oil & 5 & 10 \\
\hline Salt & 4 & 8 \\
\hline
\end{tabular}

The food itself cited as recommended salads, vegetables (38\%), fruits (13\%), fish and meat (9\%) and liver (5\%) Thirty-four percent of women didn't know what's recommended as food.

When talking about "not recommended" foods, women cited cassava $(12 \%)$, the previous day's meal $(12 \%)$, oil $(10 \%)$ and salt is also cited as an "unrecommended" food for $8 \%$ of them.

Depending on the level of knowledge of folates only $10 \%$ answered "yes", $18 \%$ "Not at all" and $72 \%$ answered vaguely. Also $8 \%$ of women know that folates are beneficial in the early stages of pregnancy compared to $92 \%$ who did not know it.

The majority of women surveyed (28\%) reported taking folate from 3 rdèmemonth, $26 \%$ from 1 st month, $20 \%$ at 4 th month, $12 \%$ in 5 th month, $4 \%$ in the second month, $2 \%$ in the 6 th month and $8 \%$ of women had not yet taken at the time of our survey.

During the survey $70 \%$ of women reported experiencing dangerous diseases during pregnancy. The four priority diseases cited were HTA, Malaria, Diabetes and Urinary Tract Infections (UTI). 
Table II: Distribution of pregnant women based on their knowledge of the complications of excessive weight gain at the csréf of commune VI of Bamako from December 2018 to January $9,2019$.

\begin{tabular}{|l|l|l|}
\hline Knowledge of complications & Squad (No.50) & $(\mathbf{\% )}$ \\
\hline During pregnancy & & \\
\hline Don't know & 27 & 54 \\
\hline Fatigues & 13 & 26 \\
\hline Edemas of lower members & 4 & 8 \\
\hline HTA & 3 & 6 \\
\hline Respiratory problems & 2 & 4 \\
\hline No complications & 1 & 2 \\
\hline During childbirth & & \\
\hline Don't know & 36 & 72 \\
\hline Fatigues & 6 & 12 \\
\hline Dystocies & 4 & 8 \\
\hline Frequent caesareans & 4 & 8 \\
\hline In the postpartum & & \\
\hline Don't know & 50 & 100 \\
\hline For the newborn & & \\
\hline Don't know & 39 & 16 \\
\hline Fetal suffering & 8 & 16 \\
\hline Fatigues & 3 & 6 \\
\hline
\end{tabular}

- Of the 50 women interviewed, 27 or $54 \%$ indicated that they did not know what the risks of weight gain exceeding recommendations during pregnancy; 3 or $6 \%$ of the women surveyed identified HTA as a complication during pregnancy. Of the other consequences of high weight gain during pregnancy, 13 or $26 \%$ of women cited fatigue, 4 or $8 \%$ reported lower limb swelling.

- Of the 50 women surveyed, 36 or $72 \%$ indicated that they did not know what the riskof complications during childbirth was, $8 \%$ of women cited dystocies and caesarean sections.

- The risk of complications for the newborn, 8 out of 50 women surveyed, or $16 \%$ reported fetal suffering.

All of the participants in our sample said they did not know the consequences of excessive weight gain during pregnancy after child birth. For $21 / 50$ women or $42 \%$ the risk of tobacco use for the child may exist even in the case of occasional consumption, $34 \%$ said they do not know the answer, $18 \%$ said that in case of high consumption and $6 \%$ in case of low consumption.

And tobacco is potentially harmful to the baby according to 33 out of 50 women surveyed (66\%).) Pour 54\% of women's maternal smoking could increase the risk of respiratory problems, slightly less sudden infant death and stunted growth $36 \%$ and $24 \%$ chacun). The risk of prematurity was less known (only by $16 \%$ of women).

Alcohol is potentially harmful to the baby according to $84 \%$ of the women surveyed, $6 \%$ felt it was not harmful and $10 \%$ said "don't know". The main effects of alcohol on the health of the child such as memory problems and physical abnormalities, aswell as known by 26 and $22 \%$ of the women surveyed respectively. The risk of pretermit and stunting were cited by 12 and $10 \%$ of womenrespectively. Problems with memory and concentration were mentioned by a minority $(10 \%$ and $8 \%)$.

\section{Information and knowledge received:}

It appears that women turned to health workers for information: $\mathrm{d}$ vers les agents de santé: midwives (84\%), gynecologists' $(12 \%)$, general practitioners $(2 \%)$. Outside the medical community, the main source of information indicated is the entourage $(2 \%)$.

Information on physical activity, risks of toxoplasmosis and listeriosis:

Women reported being informed about eating habits during pregnancy $(14 \%)$, the risks of being infected with toxoplasmosis $(12 \%)$, the possibilities of physical activity $(10 \%)$. The effects of tobacco and alcohol during this period $(6 \%$ each). On the other hand, information seems to be less developed on the risks of being contaminated with listeriosis (4\%).

\section{Pregnant women's attitudes about diet:}

It appears that quatre food groups are usually consumed by pregnant women cereal $94 \%$; meats and fish $92 \%$, other vegetables and other fruits $90 \%$; and comes last in position dark green leafy vegetables with $50 \%$. Of these, $57.14 \%$ consider their intake of dairy products to be insufficient before pregnancy; they also consider their intake of fruits and vegetables insufficient (73.47\%). About $2 \%$ of women feel that they lack salt before pregnancy.

Of the 50 women in the study $65.31 \%$ found that milk intake was insufficient during pregnancy. For meat and fish, $62 \%$ and $46.94 \%$ of women, respectively, rated these intakes better during pregnancy than before pregnancy ( 40 and $34.69 \%$ ) respectively. About $26 \%$ of women considered that they had fat during pregnancy, $4 \%$ of whom had been reduced to excessive salt intake during pregnancy.

\section{Pregnant woman's eating practices: alimentation:}

In our sample $38 \%$ said they did not monitor their diet during pregnancy, $24 \%$ monitored a little, $32 \%$ said "yes absolutely" and $2 \%$ monitored their diet instead.

\section{Tea consumption}

Of 50 pregnant women surveyed 21 or $42 \%$ reported having had tea at least once a day, $38 \%$ had taken it before and during pregnancy and $4 \%$ before pregnancy.

Pregnant woman's food diversity score:

Table III: Distribution of pregnant women by their food diversity score

\begin{tabular}{|l|l|l|}
\hline $\begin{array}{l}\text { Food Diversity } \\
\text { Score Class (SDA) }\end{array}$ & Staff & Percentage \\
\hline Low SDA & 18 & 36 \\
\hline Average SDA & 27 & 54 \\
\hline SDA acceptable & 5 & 10 \\
\hline
\end{tabular}


Only $10 \%$ of the participants in our sample had an acceptable diversity score.

\section{Commentaries and Discussions:}

We conducted a survey on the knowledge, attitudes and practices (CAP) of pregnant women in relation to their mode of feeding at the reference health centre of commune VI from 10 December to 09 January 2019 on a sample of fifty (50) pregnant womens coming to antenatal consultation at the maternity ward of the csréf de la commune VI.

The discussion of the results of our study focused on the following: socio-demographic characteristics; The knowledge, attitudes and legal practices of pregnant women and the food diversity score.

\section{Socio-demographic characteristics of pregnant women}

Regarding the characteristics of the women in ourescapelillo $\mathrm{n}$, the majority of patients were between 25 and 34 years of age (50\%) with an average of 26.84 years; Housewives were the most frequent (50\%), followed by shopkeepers (24\%), "others" (14\%) and students (12\%). Maret Caroline Poitier in 2017 found $34.7 \%$ for this age group and theaverage age was30.3 years(9). SANAGO $\mathrm{K}$ in 2011 found a predominance in the same age group of 25-34 years with a rate of $46 \%$; a non-literacy rate of $40.8 \%$, and $71.4 \%$ of housewives (10).

The percentage ofspouses in the higher education level was 36\%, while spouses with no education level representedu d'instruction représentaient $28 \% . \%$. This rate is higher than that found by Djamila 2012 in Algiers (7.4\%) (11).

\section{Knowledge of pregnant women's diet}

Pregnant women do not have a good knowledge of recommended and non-recommended foods during pregnancy. In fact, $38 \%$ of women do not know what is recommended as food, and 50\% do not know what is not recommended during pregnancy. Foods cited as recommended are foods traditionally consumed in Mali (Tô, rice, etc.).

When it comes to "non-recommended" foods, women cite cassava, the previous day's meal. They consider them harmful to their health as well as to the health of the child. Salt is also cited as an "unreased" food for $8 \%$ of them, which is not insignificant.

A small proportion of women who know folate only $10 \%$ of women know that folates are beneficial at the very beginning of pregnancy compared to $18 \%$ for a survey carried out in the Beaunois countries, by Nevers-sudnivernais et al in 2016 [12].

Among the participants, $26 \%$ reported taking folates from the $1 \mathrm{st}$ month, in France six out of ten pregnant women take folates too late [13].

Pregnant women do not know the complications of too much weight gain during pregnancy and childbirth.

Of the 50 women surveyed, $54 \%$ indicated that they did not know what the risks of weight gain exceeding recommandates during pregnancy were. Pregnant women should be informed about these risks in order to become aware of the need not to gain excessive weight. The Institute of Medicine has made recommendations for weight gain during pregnancy based on their BMI before thebeginning of pregnancy.
Women have a good knowledge of the risks of smoking to the fetus.

Tobacco is potentially harmful to the baby according to $66 \%$ of women surveyed compared to $95 \%$ according to a survey conducted in the Beaunois countries, by Nevers-sudnivernais et al. 2016(12). Among the problems ofbreastfeeding, maternal smoking may increase the risk of developing respiratoryproblems according to $54 \%$ of women, slightly less sudden infant death and stunted growth (36 and $24 \%$ of the women surveyed). The risk of prematurity is less known (only $16 \%$ of women mentioned it).

Women have a good knowledge of the risks of alcohol to the fetus. Alcohol is potentially harmful to the baby according to $84 \%$ of women surveyed on the other hand some of the risks to the health of the child are unknown; according to a survey conducted in the Beaunois countries by Nevers-Sud Nivernais et al in 2016 the rate was $72 \%[12]$.

\section{Information and knowledge received}

For information, women turn first to health workers: midwives (84\%), gynaecologists (12\%), general practitioners (2\%). Outside the medical community, the main source of information indicated is the entourage (2\%). Whereas according to the survey carried out in the Beaunois countries by Nevers-Sud Nivernais et al in 2016 to find out, womenturnedfirst to health professionals: gynaecologists $(65 \%)$, midwives $(56 \%)$ and general practitioners $(26 \%)$, the main sources of information indicated outside the medical environmentis the surrounding $(46 \%)(12)$.

Information on physical activity, the risks of toxoplasmosis and listeriosis to be enhanced:

Women reported being informed about eating habits during pregnancy $(14 \%)$, the risks of being infected with toxoplasmosis $(12 \%)$, the possibilities of physical activity $(10 \%)$. The effects of tobacco and alcohol during this period (6\% each). On the other hand, information seems to be less developed on the risks of being contaminated with listeriosis (4\%). In the Countries beaunois Nevers-South Nivernais et al. In 2016 found 78\% of women reporting being informed about eating habits to adopt during pregnancy, $83 \%$ about the risks of being contaminated by toxoplasmosis, 80 and $79 \%$ about the effects of tobacco and alcohol during pregnancy [12].

\section{Pregnant Women's Attitudes to Food}

The eating behaviour of the women in our sample seems very paradoxical. They are fully aware of the role of food during pregnancy, but they do not refer to it spontaneously. Even if they consider essential and the variety and quantity of the diet could be explained by a low purchasing power of the household.

The usual diet of these women is mostly cereals: rice (46\%), to $(20 \%)$ and legumes. Albane in Burkina Faso in 2005 found for rice) $(91.2 \%)$ and to $(91.8 \%)$ are the most consumed [14].

Cereal dishes are usually accompanied by various sauces (green leaf sauce, tomato, peanut), which are the main source of variety in the diet.

Deficits have also been perceivedby these women, in terms of their diet during pregnancy and even before. A majority of them con- 
sidered their supply of meat and fish insufficient. "Money" was mentioned by the majority of women.

These foods are sources of protein and "heme" iron essential for a woman because it is best absorbed. Reprieve iron reprieve anemia during pregnancy can result in a 2.5 times higher risk of preterm birth and a 3 times higher risk of low birth weight.

\section{Pregnant women's eating practices}

In our sample 38\% say they do not monitor their diet during pregnancy this rate is slightly higher than that of Nevers-South Nivernais et al. 2016 in the country of Beaumois which is $36.7 \%$. Among the women $10 \%$ were in pre-pregnancy sports and $4 \%$ were in the pregnancy. Caroline Poitier in 2017 found respectively 35\% and $28 \%$. It is advisable to practice at least 30 minutes of moderate physical activity per day during pregnancy.

\section{Pregnant woman's diversity score}

In our study $36 \%$ of the parturients have alow level of alien diversity. The ENSAN survey showed low dietary diversity and consumption of essential micronutrients (proteins, fats, vitamins) fromemeat, milk, eggs, oils, fruits and vegetables are very low [14].

\section{Conclusion}

Following this CAP study of pregnant women in relation to their diet conducted on 50 pregnant women aged 18 to 42 during the prenatal consultation at the Reference Health Centre of commune VI from 10 December to 09 January 2019, we had the following results: half of the pregnant women were housewives and have a basic education level; women have a poor and low diet in terms of the intake of certain foods such as meat, poisson or dairy products; more than a third had a low diversity score.

They do not have a good knowledge of certain subjects such as recommended and l' l' non-recommended foods during pregnancy, balanced diet, complication of excessive weight gain during pregnancy, folate, toxoplasmosis, listeriosis, physical activity. So do they have a good knowledge of the risks of tobacco and alcohol to the fetus? We also noticed that women feel little concern about diet and weight gain in general and folates were taken by the majority only from the 3rd month of pregnancy.

We believe that these results should be used to improve women's nutrition knowledge, attitudes and practices at the Central UK in Bamako.

\section{References}

1. BOOG G (2016) The obstetric consequences of abnormal weight gain. Pyrenean Days of Gynecology. Tarbes 1: 54.

2. UNICEF. Nutrition (2016) http://www.unicef.org/wcaro/ french/4493 4568.html.

3. WHO (2011) Guidelines: Vitamin A supplementation in women during the postnatal period. Geneva.

4. BERJER J. Berger J, Dillon J C (2002) Iron Deficiency Control Strategies in Developing Countries. Health Papers 12:2230 .

5. Algosophette Association (2016) Hunger and malnutrition around the world; Lokilyluxe Design, Montpellier http:// www.algosophette.com/association/spiruline.html.

6. INSTAT/MPATP, INFO-STAT and ICF International. Planning and Statistics Unit (CPS/SSDSPF), National Institute of Statistics Demographic and Health Survey in Mali 20122013. Rockville, Maryland, USA: CPS, INSTAT, INFO-STAT and ICF International. 2019.

7. National Directorate of Health (2013) Mali National Nutrition Policy 2013: 40.

8. MARET. C. (2017) Study on women's diet and weight gain based on their profile during pregnancy 23-35.

9. SANOGO K (2001) Mothers' knowledge and practices in early childhood feeding in the village of Point $\mathrm{G}$ in Commune III of the District of Bamako in 2011 48-52.

10. Djamila T M (2012) Nutritional and socio-demographic status of a cohort of pregnant women of el khroub (constantine, Algeria). Impact on weight; Constantine, Algeria 117-130.

11. Nevers-South Nivernais (2016) Knowledge and behaviours of pregnant women in nutrition, tobacco and alcohol Country Beaunois in 2016: 8 .

12. Albane (2005) The eating behaviours of pregnant women in Ouagadougou, (Burkina Faso) in 2005: 25-28.

13. Ministry of Agriculture (2018) National Survey on Food and Nutrition Security Mali.
Copyright: (C2020 Mamadou Berthe, et al. This is an open-access article distributed under the terms of the Creative Commons Attribution License, which permits unrestricted use, distribution, and reproduction in any medium, provided the original author and source are credited. 